\title{
Fibrinogen concentrate replacement in ischemic stroke patients after recombinant tissue plasminogen activator treatment
}

\author{
Laura Vandelli, ${ }^{1, A-E}$, Marco Marietta ${ }^{2, A, E}$, Tommaso Trenti, ${ }^{3, B, E}$, Manuela Varani ${ }^{3, B, E}$, Guido Bigliardi ${ }^{1, B, E}$, \\ Francesca Rosafio ${ }^{1, B, E}$, Maria Luisa Dell'Acqua ${ }^{1, B, E}$, Livio Picchetto ${ }^{1, B, E}$, Paolo Nichelli ${ }^{1, B, E}$, Andrea Zinii ${ }^{1, A, C-F}$ \\ ${ }^{1}$ Stroke Unit, Neurology Clinic, Department of Neuroscience, Nuovo Ospedale Civile S. Agostino-Estense, University of Modena and Reggio Emilia, Modena, Italy \\ ${ }^{2}$ Department of Oncology and Hematology, Polyclinic of Modena, University of Modena and Reggio Emilia, Modena, Italy \\ ${ }^{3}$ Clinical Pathology - Toxicology Department, Nuovo Ospedale Civile S. Agostino-Estense, Azienda Unita' Sanitaria Locale di Modena, Italy \\ A - research concept and design; $B$ - collection and/or assembly of data; $C$ - data analysis and interpretation; \\ $D$ - writing the article; $E$ - critical revision of the article; $F$ - final approval of the article
}

Address for correspondence

Andrea Zini

E-mail: andrea.zini@me.com

Funding sources

None declared

Conflict of interest

None declared

Received on November 15, 2016

Reviewed on January 10, 2017

Accepted on January 31, 2018

Published online on December 3, 2018

Cite as

Vandelli L, Marietta M, Trenti T, et al. Fibrinogen concentrate replacement in ischemic stroke patients after recombinant tissue plasminogen activator treatment. Adv Clin Exp Med. 2019;28(2):219-222. doi:10.17219/acem/84936

DOI

10.17219/acem/84936

Copyright

Copyright by Author(s)

This is an article distributed under the terms of the

Creative Commons Attribution Non-Commercial License

(http://creativecommons.org/licenses/by-nc-nd/4.0/)

\begin{abstract}
Background. Post-thrombotic intracerebral hemorrhage (ICH) is experienced by $6-8 \%$ of stroke patients and is associated with multiple factors, including acquired coagulopathy induced by the thrombolytic drug.

Objectives. The objective of this study was to assess the outcome of the intravenous (IV) administration of fibrinogen concentrate in a series of acute stroke patients who developed iatrogenic fibrinogen critical depletion after IV thrombolysis.
\end{abstract}

Material and methods. Of the 39 ischemic stroke patients treated with IV thrombolysis with a severe hypofibrinogenemia requiring infusion with IV fibrinogen concentrate, 30 patients were treated with $2 \mathrm{~g}$ of IV recombinant tissue plasminogen activator (rt-PA), followed by further doses until the fibrinogen level reached $200 \mathrm{mg} / \mathrm{dL}$ in hemorrhagic patients or $100 \mathrm{mg} / \mathrm{dL}$ in non-hemorrhagic patients, and 9 were treated with IV rt-PA followed by endovascular thrombectomy.

Results. Pre- and post-thrombolysis National Institutes of Health Stroke Scale (NHISS) scores were statistically different for the Cochran-Mantel-Haenszel test overall ( $p=0.0002)$, at 24-hour evaluation ( $p=0.0455)$ and at 7 -day assessment $(p=0.0006)$. Within the first 7 days post-thrombolysis, the brain computed tomography (CT) scans showed that 20/39 (51.28\%) patients had ICH. Of the whole sample, 25.6\% of the ICH patients had symptomatic intracerebral hemorrhage (SICH), according to National Institute of Neurological Disorders and Stroke (NINDS) classification. After rt-PA treatment, the median pre-thrombolysis fibrinogenemia of $332 \mathrm{mg} / \mathrm{dL}$ significantly dropped to $133 \mathrm{mg} / \mathrm{dL}(p<0.0001)$. After the fibrinogen concentrate infusion, the median level of fibrinogenemia rose to $160 \mathrm{mg} / \mathrm{dL}$, which was significantly higher than the median postthrombolysis levels $(p<0.0001)$. Recanalization was observed in 25/28 patients (89.29\%): complete in 18 and partial in 7 patients. After fibrinogen IV infusion, no thrombotic complications were seen in 37 out of 39 patients (94.77\%); 2/39 (0.05\%) patients experienced a pulmonary embolism, 1 of them a segmental one.

Conclusions. This study showed the clinical safety of administering IV fibrinogen concentrate in order to increase plasma fibrinogen levels in a series of acute stroke patients with iatrogenic fibrinogen depletion after IV thrombolysis.

Key words: ischemic stroke, fibrinogen concentrate replacement, recombinant tissue plasminogen activator 


\section{Background}

Intravenously (IV) recombinant tissue plasminogen activator (rt-PA) is the recommended treatment for eligible acute stroke patients ${ }^{1}$ associated with an increased risk of intracerebral hemorrhage ( $\mathrm{ICH})$ that mainly occurs within $24-36 \mathrm{~h}$ after thrombolysis. About 6-8\% of stroke patients undergoing IV thrombolysis experienced symptomatic intracerebral hemorrhage $\mathrm{sICH}$, as defined by $\mathrm{Na}$ tional Institute of Neurological Disorders and Stroke NINDS), and an additional 1.6-3.6\% of them had major systemic bleeding events. ${ }^{2,3}$

Numerous studies have identified different hemorrhagic risk factors for post-thrombolytic $\mathrm{ICH}$, but none was recognized as a determinant, given the possible association of multiple factors. Another important hemorrhagic risk factor seems to be an acquired coagulopathy induced by the thrombolytic drug itself, due to incomplete fibrin-specificity causing a fibrinogen consumption and formation of fibrinogen degradation products, which may lead to a pro-hemorrhagic state supporting bleeding complications. ${ }^{4-6}$

This observational study assessed the clinical outcome of the IV administration of fibrinogen concentrate in a series of acute stroke patients who developed iatrogenic fibrinogen critical depletion after IV thrombolysis.

\section{Material and methods}

In the Stroke Unit in Modena University Hospital (Italy), from among 700 ischemic stroke patients treated with IV thrombolysis, data of 39 patients who had experienced severe hypofibrinogenemia and required infusion with IV fibrinogen concentrate (Haemocomplettan P) was collected: 30 patients were treated with IV rt-PA (76.9\% of cases) and 9 were treated with IV rt-PA followed by endovascular thrombectomy (23.1\% of cases). Fibrinogen values pre-rt-PA infusion and $2 \mathrm{~h}$ after the end of the treatment were measured.

In collaboration with the Modena Hospital hematology consultant, to manage the iatrogenic fibrinogen critical depletion after IV thrombolysis, we created hospital standard operating procedures (SOPs) for fibrinogen supplementation considering, as a threshold level for severe hypofibrinogenemia post-thrombolysis, an absolute value $<100 \mathrm{mg} / \mathrm{dL}$ of fibrinogen level for patients without $\mathrm{ICH}$, and a threshold $<200 \mathrm{mg} / \mathrm{dL}$ in case of $\mathrm{ICH}$ or, in both cases, a relative decrease of fibrinogen levels pre- and post-thrombolysis) $>30 \%{ }^{4}$

Patients fulfilling the inclusion criteria (fibrinogen supplementation considering, as a threshold level for severe hypofibrinogenemia post-thrombolysis, an absolute value $<100 \mathrm{mg} / \mathrm{dL}$ of fibrinogen level for patients without $\mathrm{ICH}$, and a threshold $<200 \mathrm{mg} / \mathrm{dL}$ in case of $\mathrm{ICH}$ or, in both cases, a relative decrease of fibrinogen levels pre- and post-thrombolysis) $>30 \%$ ) were treated with $2 \mathrm{~g}$ of IV fibrinogen, followed by further doses until the fibrinogen level reached $200 \mathrm{mg} / \mathrm{dL}$ in hemorrhagic patients or $100 \mathrm{mg} / \mathrm{dL}$ in non-hemorrhagic patients (Haemocomplettan P mean dose $2 \mathrm{~g} ; 5$ patients with $4 \mathrm{~g}$ and 2 patients with $6 \mathrm{~g}$ ).

\section{Statistical analysis}

Patients' characteristics will be summarized by means of cross-tabulations for categorical variables or by means of quintiles for continuous variables. Distribution differences of continuous variables over time were assessed using the Mann-Whitney U test. All tests were two-sided, accepting $\mathrm{p}<0.05$ as indicating a statistically significant difference. Analyses were performed by SAS v. 9.1.3 statistical software (SAS Institute, Cary, USA).

\section{Results}

Among the 39 patients enrolled, there were 15 females (38.5\%) and 24 males (61.5\%), with a median age of 78 years (range: $30-96$ years) and with a baseline median National Institutes of Health Stroke Scale (NIHSS) clinical stroke severity grade of 14 (range: 2-24). Table 1 provides a short description of patient characteristics.

The overall difference between the NIHSS scores pre- and post-thrombolysis was statistically significant ( $\mathrm{p}=0.0002)$, as well as the difference between the NIHSS scores pre- and post-thrombolysis at 24-hour evaluation ( $\mathrm{p}=0.0455)$, and between the NIHSS scores

Table 1. Patient characteristics

\begin{tabular}{|c|c|c|}
\hline \multicolumn{2}{|l|}{$\begin{array}{l}\text { Age } \\
\text { mean (range) [years] }\end{array}$} & $78.4(30.9-96.7)$ \\
\hline \multirow{2}{*}{$\begin{array}{l}\text { Sex } \\
n,[\%]\end{array}$} & M & $24(61.5)$ \\
\hline & $\mathrm{F}$ & $15(38.5)$ \\
\hline \multirow{2}{*}{$\begin{array}{l}\text { Type of thrombolysis, } \\
n,[\%]\end{array}$} & IV & $31(79.5)$ \\
\hline & $\begin{array}{l}\text { IV plus endovascular } \\
\text { treatment }\end{array}$ & $8(20.5)$ \\
\hline \multicolumn{2}{|c|}{$\begin{array}{l}\text { Fibrinogen pre-thrombolysis, } \\
\text { median (range) }[\mathrm{mg} / \mathrm{dL}]\end{array}$} & $332.0(170.0-815.0)$ \\
\hline \multicolumn{2}{|c|}{$\begin{array}{l}\text { Fibrinogen pre-infusion, } \\
\text { median (range) }[\mathrm{mg} / \mathrm{dL}]\end{array}$} & $133.0(18.0-231.0)$ \\
\hline \multicolumn{2}{|c|}{$\begin{array}{l}\text { Fibrinogen post-infusion, } \\
\text { median (range) [mg/dL] }\end{array}$} & $160.5(56.0-337.0)$ \\
\hline \multicolumn{2}{|c|}{$\begin{array}{l}\text { Reduction pre-thrombolysis-pre-infusion, } \\
\text { median (range) [\%] }\end{array}$} & $66.3(0.0-97.8)$ \\
\hline \multicolumn{2}{|c|}{$\begin{array}{l}\text { NIHSS pre-thrombolysis, } \\
\text { median (range) }\end{array}$} & $14.0(2.0-24.0)$ \\
\hline \multicolumn{2}{|l|}{$\begin{array}{l}\text { NIHSS after } 24 \mathrm{~h} \text {, } \\
\text { median (range) }\end{array}$} & $9.0(0.0-31.0)$ \\
\hline \multicolumn{2}{|l|}{$\begin{array}{l}\text { NIHSS after } 7 \text { days, } \\
\text { median (range) }\end{array}$} & $5.0(0.0-37.0)$ \\
\hline
\end{tabular}

IV - intravenous; M - male; F - female; NIHSS - National Institutes of Health Stroke Scale. 


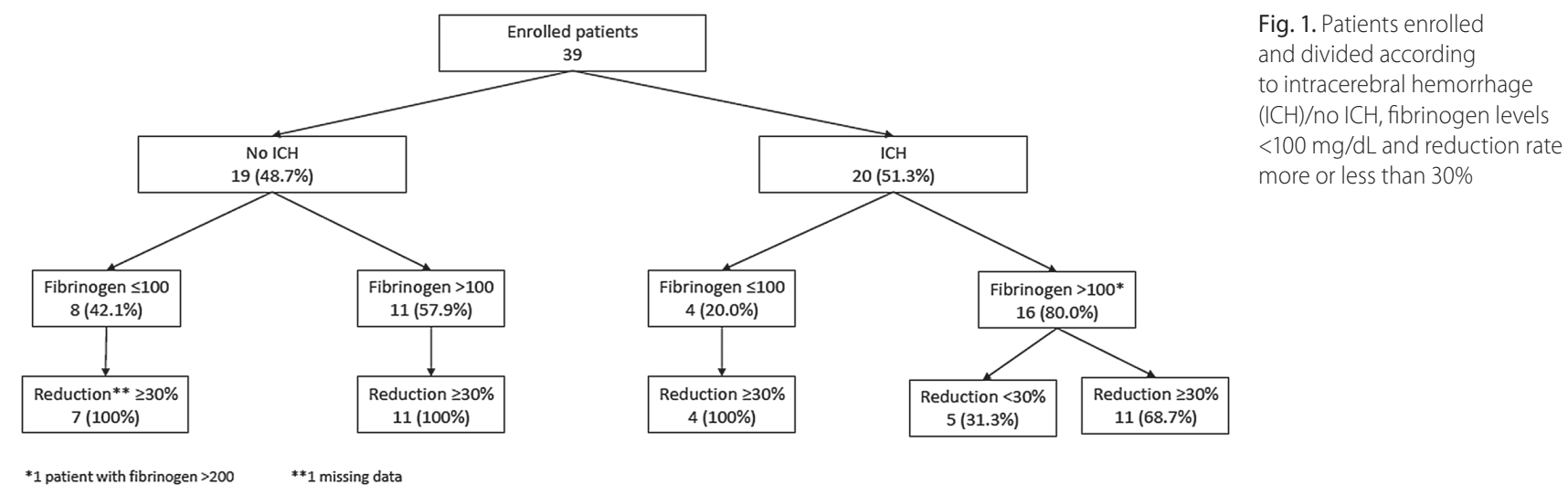

pre- and post-thrombolysis at 7-day assessment $(\mathrm{p}=0.0006)$.

After $24 \mathrm{~h}$ post-thrombolysis, the median NIHSS score was 9 ( $\min 0, \max 31)$ and after 7 days it was $5(\min 0, \max 37)$. The brain computed tomography (CT) scans performed within the first 7 days post-thrombolysis showed that 20 out of 39 patients $(51.28 \%)$ had ICH (1 with hemorrhagic infarction type 1 (H1) and 6 with parenchymal hemorrhage type 1 (PH1); 4 with hemorrhagic infarction type $2(\mathrm{H} 2)$, and 9 with parenchymal hemorrhage type 2 (PH2) (Fig. 1).

The patients had symptomatic and asymptomatic hemorrhages. Symptomatic hemorrhage, defined according to the NINDS classification, was present in half of the ICH patients (25.6\% of the whole sample). The median prethrombolysis fibrinogenemia was $332 \mathrm{mg} / \mathrm{dL}$ (range: 170-815 mg/dL), which significantly dropped to $133 \mathrm{mg} / \mathrm{dL}$ (range: $18-231 \mathrm{mg} / \mathrm{dL}$ ( $\mathrm{p}<0.0001)$ after rt-PA, with a median drop rate of $60 \%$.

After the infusion of fibrinogen concentrate, the median level of fibrinogenemia rose to $160 \mathrm{mg} / \mathrm{dL}$ ( $\min 56 \mathrm{mg} / \mathrm{dL}$, $\max$ $337 \mathrm{mg} / \mathrm{dL}$ ), was significantly higher than the post-thrombolysis median levels ( $\mathrm{p}<0.0001)$, and with a median decrease of $-64.61 \mathrm{mg} / \mathrm{dL}$ ( $\min -97.8 \mathrm{mg} / \mathrm{dL}, \max 42.2 \mathrm{mg} / \mathrm{dL}$ ) compared with the pre-thrombolysis levels.

Subsequent controls showed a recanalization in 25 out of 28 patients $(89.29 \%)$ : complete in $18 / 28$ patients $(46.15 \%)$ and partial in $7 / 28$ patients (17.95\%). Hence, a complete or partial recanalization was observed in more than $60 \%$ of the patients. Data from 11 out of 28 patients (28.19\%) was not available due to missing neurological or radiological assessments.

Regarding the safety of fibrinogen supplementation with Haemocomplettan P, in this case a series of 37 out of 39 patients $(94.77 \%)$ had no thrombotic complications after fibrinogen IV infusion, while $2 / 39$ (0.05\%) patients experienced a pulmonary embolism, 1 of them a segmental one. For 1 of these 2 cases, further investigations gave a subsequent diagnosis of a metastatic pancreatic tumor, which likely had a relevant role in this case, given the wellknown paraneoplastic pro-thrombotic condition of pancreatic cancer.

\section{Discussion}

In this study, we selected a treatment based on the supplementation of fibrinogen concentrate, taking into account the pathogenesis and mechanism of early rt-PA coagulopathy and the allergic infections and hypervolemic concerns likely associated with fresh frozen plasma and cryoprecipitate.

Most of the patients were supplemented with a limited amount of fibrinogen concentrate ( $2 \mathrm{~g})$, which significantly increased their final fibrinogen levels, mainly to counteract the fibrinogen consumption due to the previous thrombolytic procedure. The final median fibrinogen level of $64.61 \mathrm{mg} / \mathrm{dL}$ was lower than pre-rt-PA levels. The clinical conditions of the patients globally improved, with a significant decrease of the median NIHSS score from 14 at baseline to 9 after $24 \mathrm{~h}$ post-thrombolysis, and to 5 after 7 days.

Relevant worsening after fibrinolytic treatment was limited to 6 patients; 5 of them experienced a severe sICH associated with fibrinogen depletion and infusion of IV fibrinogen concentrate after detection of post-thrombolysis $\mathrm{ICH}$. This data could suggest the possible role of hypofibrinogenemia in increasing the risk of bleeding (in particular for sICH) and subsequent poor clinical outcome.

Several studies have highlighted that a critical drop in fibrinogen levels after IV thrombolysis, due to so-called "early rt-PA coagulopathy", is associated with an increased risk of bleeding. 5,6 Apart from a pro-hemorrhagic effect, fibrin and fibrinogen concentrates may have a direct role in the coagulation cascade, as reported by several studies, whereby the fibrinogen supplementation is applied with anti-hemorrhagic purposes in patients with severe hemorrhages and related fibrinogen deficiency following trauma, surgery, etc. ${ }^{7-10}$

In a previous study of Vandelli et al., performed on 104 ischemic stroke patients undergoing rt-PA therapy, the subsequent bleeding rate in the low fibrinogen group was significantly higher $(43.9 \%)$ than in the normal fibrinogen group (9.5\%; odds ratio $(\mathrm{OR})=7.43, \mathrm{p}=0.001$ ). The fibrinogen depletion emerged as a highly significant predictor for bleeding risk, underlying a close temporal 
relationship with the manifestation of hemorrhage, and accounted for approx. $40 \%$ of bleeding events. ${ }^{4}$

Currently, in the absence of evidence-based guidelines for managing thrombolysis-associated $\mathrm{SICH}$, current clinical management is empiric and based on expert opinions, and includes the infusion of fresh frozen plasma, cryoprecipitate or fibrinogen concentrate. ${ }^{11}$ In a previous study conducted on patients with occlusions of the intracranial internal carotid artery or the first segment of the middle cerebral artery (or both), IV rt-PA treatment resulted in early reperfusion in $13-50 \%$ of the subjects. ${ }^{12}$ The high reperfusion rate in our sample shows that the infusion of fibrinogen does not reduce the rate of recanalization; hence, it does not affect negatively the chances of the vessel reopening.

Medical literature regarding the rate of thrombotic complication after fibrinogen concentrate use in stroke patients is relatively lacking. However, experiences in cardiac surgery showed that administration of fibrinogen concentrate was not associated with an increased risk of mortality and thromboembolic events, ${ }^{13}$ and a recent Cochrane review (www.cochranelibrary.com) on fibrinogen concentrate in bleeding patients did not show any adverse events such as thrombotic episodes following the use of fibrinogen concentrate. ${ }^{14}$ Moreover, thromboembolic complications reported by a large observational study occurred as pulmonary embolism in $0.51 \%$, deep vein thrombosis (DVT) in $0.74 \%$ and venous thromboembolism (VTE) in $1.71 \%$ of $14,109,000$ hospitalized patients with stroke not treated with fibrinogen concentrate. ${ }^{15}$

\section{Conclusions}

This observational study showed the clinical safety of administering IV fibrinogen concentrate in order to increase plasma fibrinogen levels in a series of acute stroke patients developing iatrogenic fibrinogen critical depletion after IV thrombolysis. Further and broader studies are needed to evaluate the clinical efficacy as the rationale for administering IV fibrinogen concentrate in order to reduce the risk of intracranial hemorrhage when administered before hemorrhagic complication or to prevent hematoma expansion when administered after bleeding.

\section{References}

1. Powers WJ, Derdeyn CP, Biller J, et al; American Heart Association Stroke Council. 2015 American Heart Association / American Stroke Association focused update of the 2013 guidelines for the early management of patients with acute ischemic stroke regarding endovascular treatment: A guideline for healthcare professionals from the American Heart Association / American Stroke Association. Stroke. 2015;46(10):3024-3039.

2. Graham GD. Tissue plasminogen activator for acute ischemic stroke in clinical practice: A meta-analysis of safety data. Stroke. 2003;34(12): 2847-2850.

3. Wahlgren N, Ahmed N, Davalos A, et al; SITS-MOST Investigators. Thrombolysis with alteplase for acute ischemic stroke in the Safe Implementation of Thrombolysis in Stroke-Monitoring Study (SITSMOST): An observational study. Lancet. 2007;369(9558):275-282.

4. Vandelli L, Marietta M, Gambini ME, et al. Fibrinogen decrease after intravenous thrombolysis in ischemic stroke patients is a risk factor for intracerebral hemorrhage. J Stroke Cerebrovasc Dis. 2015;24(2): 394-400.

5. Trouillas P, Derex L, Philippeau F, et al. Early fibrinogen degradation coagulopathy is predictive of parenchymal hematomas in cerebral rt-PA thrombolysis: A study of 157 cases. Stroke. 2004;35(6):1323-1328.

6. Matosevic B, Knoflach M, Werner P, et al. Fibrinogen degradation coagulopathy and bleeding complications after stroke thrombolysis. Neurology. 2013;80(13):1216-1224.

7. Danés AF, Cuenca LG, Bueno SR, Mendarte Barrenechea L, Ronsano JB. Efficacy and tolerability of human fibrinogen concentrate administration to patients with acquired fibrinogen deficiency and active or in high-risk severe bleeding. Vox Sang. 2008;94(3):221-226.

8. Gollop ND, Chilcott J, Benton A, Rayment R, Jones J, Collins PW. National audit of the use of fibrinogen concentrate to correct hypofibrinogenemia. Transfus Med. 2012;22(5):350-355.

9. Weiss G, Lison S, Glaser M, et al. Observational study of fibrinogen concentrate in massive hemorrhage: Evaluation of a multicenter register. Blood Coagul Fibrinolysis. 2011;22(8):727-734.

10. Fenger-Eriksen $C$, Lindberg-Larsen $M$, Christensen $A Q$, Ingerslev J, Sørensen B. Fibrinogen concentrate substitution therapy in patients with massive hemorrhage and low plasma fibrinogen concentrations. Br J Anaesth. 2008;101(6):769-773.

11. Hemphill JC, Greenberg SM, Anderson CS, et al; American Heart Association Stroke Council; Council on Cardiovascular and Stroke Nursing; Council on Clinical Cardiology. Guidelines for the management of spontaneous intracerebral hemorrhage: A guideline for healthcare professionals from the American Heart Association / American Stroke Association. Stroke. 2015;46(7):2032-2060.

12. De Silva DA, Brekenfeld $C$, Ebinger $M$, et al; Echoplanar Imaging Thrombolytic Evaluation trial (EPITHET) Investigators. The benefits of intravenous thrombolysis relate to the site of baseline arterial occlusion in the Echoplanar Imaging Thrombolytic Evaluation Trial (EPITHET). Stroke. 2010;41(2):295-299.

13. Fassl J, Lurati Buse G, Filipovic M, et al. Perioperative administration of fibrinogen does not increase adverse cardiac and thromboembolic events after cardiac surgery. Br J Anaesth. 2015;114(2):225-234.

14. Wikkelsø A, Lunde J, Johansen $M$, et al. Fibrinogen concentrate in bleeding patients. Cochrane Database Syst Rev. 2013;8:CD008864.

15. Skaf E, Stein PD, Beemath A, Sanchez J, Bustamante MA, Olson RE. Venous thromboembolism in patients with ischemic and hemorrhagic stroke. Am J Cardiol. 2005;96(12):1731-1733. 